\title{
Tautomerism in acyl-pyrazolones and in a novel photolysis product-importance and impact of the accurate localization of hydrogen atoms in crystal structures
}

\author{
Lorraine A. Malaspina ${ }^{1}$ - Allan H. White ${ }^{2}$ - Dieter Wege ${ }^{2} \cdot$ Michael B. Tolmie $^{2}$. \\ Brian W. Skelton ${ }^{2} \cdot$ Simon Grabowsky $^{1,2}$ (1)
}

Received: 7 March 2017 / Accepted: 10 July 2017 /Published online: 7 August 2017

(C) Springer Science+Business Media, LLC 2017, Corrected publication August/2017

\begin{abstract}
Acyl-pyrazolones exist in four different tautomeric forms (two keto and two enol) in crystal structures. Routine crystal structure refinements using an independent atom model and routine isolated-molecule calculations fail in locating the mobile hydrogen atoms accurately in 22 investigated acylpyrazolone examples. However, a combination of both within the framework of quantum crystallography represented by the method of Hirshfeld atom refinement accurately locates the mobile hydrogen atom in a resonance-assisted hydrogen bond of title compound $\mathbf{3}$, a novel photolysis product. The impact of the hydrogen atom position on the resonance system of the nonhydrogen framework of the various tautomers is discussed, and the importance of intermolecular interactions for the positioning of the hydrogen atom is highlighted.
\end{abstract}

Keywords Tautomerism $\cdot$ Resonance-assisted hydrogen bond $\cdot$ Hirshfeld atom refinement $\cdot$ Hydrogen atom parameters $\cdot$ Photolysis

The original version of this article was revised: a modification has been made to the layout of Table 2 .

This paper is dedicated to Professor Louis J. Massa on the occasion of his Festschrift.

Allan H. White is deceased.

Electronic supplementary material The online version of this article (doi:10.1007/s11224-017-1005-0) contains supplementary material, which is available to authorized users.

Simon Grabowsky

simon.grabowsky@uni-bremen.de

1 Universität Bremen, Fachbereich 2, Biologie/Chemie, Institut für Anorganische Chemie und Kristallographie, Leobener Str. NW2, 28359 Bremen, Germany

2 The University of Western Australia, School of Molecular Sciences, M310, Perth, WA 6009, Australia

\section{Introduction}

Tautomerism is a form of constitutional isomerism in that the two isomers readily interconvert into each other [1]. Most commonly a proton is relocated, so the tautomerization reaction is a proton transfer reaction. Prototropic tautomerism is highly relevant to biology since the neutral and zwitterionic forms of amino acids are tautomers of each other, and since overall proton transfer reactions are the most common biochemical reactions [2]. Keto-enol tautomerism is the textbook example for prototropic tautomerism, with the keto form usually being significantly more stable. However, in 1,3-diketones, such as the acyl-pyrazolones investigated in this study (Scheme 1), the proton closes a six-membered ring in the enol form and hence facilitates energetic stabilization of the enol form by resonance [3-6]. The resulting intramolecular hydrogen bond is consequently called a resonance-assisted hydrogen bond (RAHB) [7], and the proton is displaced significantly from the donor atom, so that the barrier of transfer to the acceptor atom is low (forms $\mathbf{A}$ and $\mathbf{B}$ in Scheme 1). Therefore, RAHBs belong to the class of low-barrier hydrogen bonds that play a significant mechanistic role in enzymatic proton transfer reactions $[8,9]$. Small molecules that comprise RAHBs such as the acyl-pyrazolones in this study are sometimes used as model compounds to investigate proton transfer reactions [10]. The two types $\mathbf{A}$ and $\mathbf{B}$ of the enol form are also tautomers relative to each other.

We became interested in the compound class of acylpyrazolones (more precisely, 4-acyl-1-phenyl-3-methylpyrazol-5-ones and closely related derivatives) because there is a variety of crystal structures of them in the literature (retrievable through the Cambridge Structural Database [11]) in both keto and enol forms, although the rationale above would exclude the keto form. In the keto form, the proton is situated at the unsubstituted pyrazole nitrogen atom, with the two 
Scheme 1 Definition of the four tautomer forms $\mathbf{A}-\mathbf{D}$ observed in the crystal structures of acylpyrazolones

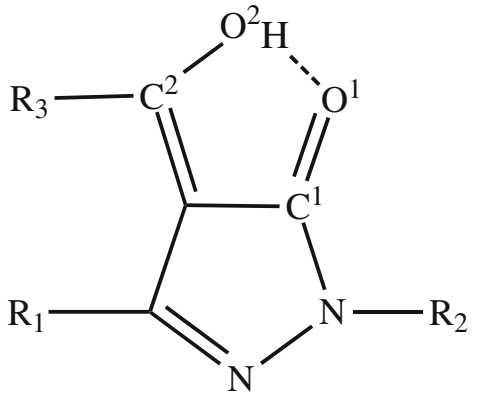

A

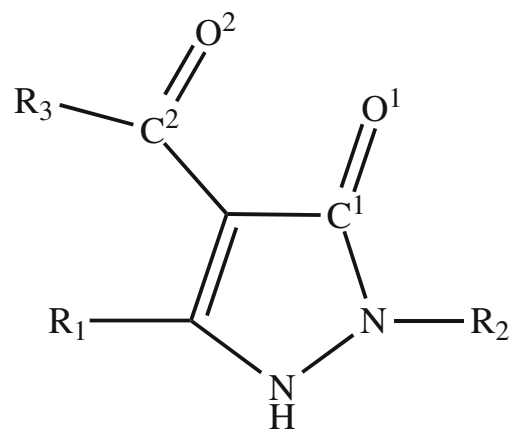

C

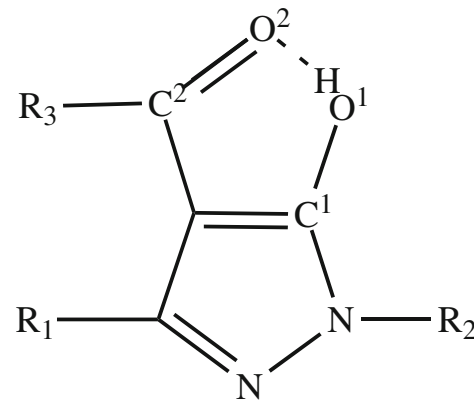

B

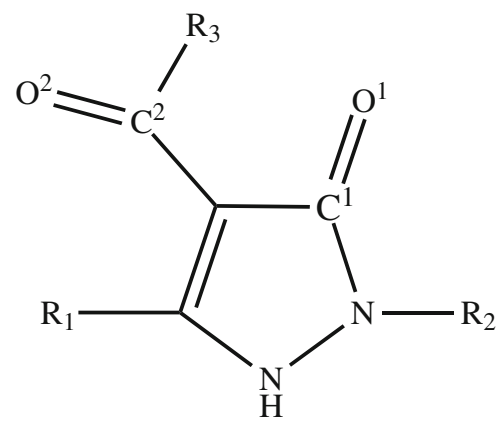

D carbonyl groups either remaining cis relative to each other (form $\mathbf{C}$, Scheme 1), or turning away, which we call the trans form (form D, Scheme 1).

We analyse five keto forms [12-16] (Table 1) and 17 enol forms [12, 14, 15, 17-29] (Table 2). In two cases, both tautomeric forms are found within two different crystal structures $[12,15]$, a phenomenon which is called desmotropy [30]. It is not a form of polymorphism because the two tautomers should be considered two different molecules [31]. There are broader reviews primarily concerned with metal complexes of acyl-pyrazolones ligands [32], but as far as we are aware, there has been no critical analysis of the different forms found in these acyl-pyrazolone pro-ligand structures themselves or any associated theoretical exploration of their relative intrinsic stabilities. We turn our attention to these aspects of this system in the present contribution, with special reference to the 1-phenyl-3-methyl compounds, which provide the preponderance of the known data, and so constitute a useful platform with a quasi-planar constant core for their comparison.

In order to study tautomerism in crystal structures, the hydrogen atom position must be secured accurately. This is not always a trivial task, especially with routine X-ray data. For the compound class of acyl-pyrazolones, no useful neutron-diffraction study exists to the best of our knowledge. However, even if the hydrogen atom in question cannot be located from a Fourier difference map of the X-ray data unambiguously, the non-hydrogen bond lengths change considerably between tautomers [30], so that they can be used to differentiate between keto and enol forms across the range of studied compounds (Scheme 1). However, the enolic tautomers
$\mathbf{A}$ and $\mathbf{B}$ are more difficult to discern because the proton can be significantly displaced, or even located symmetrically between donor and acceptor atoms. Therefore, ways of accurately determining the hydrogen atom position in X-ray data refinements are necessary. We [33] and others [34] have recently summarized available techniques of hydrogen atom treatments in X-ray data refinements. Those techniques include free refinement against Xray data within the conventional independent atom model (IAM) of spherical atomic scattering factors, normalization relative to averaged data from neutron diffraction $[35,36]$, constraints to values from theoretical calculations [37, 38] or improved techniques of X-ray data refinement employing aspherical scattering factors, such as multipole data-base techniques [39-41] or Hirshfeld atom refinement (HAR) [42, 43].

HAR uses tailor-made aspherical scattering factors for X-ray data refinements and has proven to be able to locate hydrogen atoms as accurately and precisely as neutron-diffraction experiments can [44], including hydrogen atoms in low-barrier hydrogen bonds [45]. We believe that HAR is one of the central milestones of quantum crystallography [46], as originally developed and defined by Massa and others [47, 48]. HAR-derived bond lengths involving hydrogen atoms $(\mathrm{A}-\mathrm{H})$ using a resolution of $0.8 \AA$ are as accurate and precise as those using high resolution $(d<0.6 \AA)$ [44], but that was shown based on high-resolution data sets pruned down to low resolution. This means that the average intensities of the reflections in the pruned data sets were significantly higher than what is available in routine low-order data sets, where the upper resolution limit is determined by the weak 
Table 1 Details for pyrazolone crystal structures in the keto form and selected bond distances $(\AA)$ not involving the hydrogen atom in question because it is not determined accurately (see Fig. 1 for details, and compare to Table 3). Tables with complete geometric details are deposited with the Supporting Information (Table S2)

\begin{tabular}{llllll}
\hline $\mathrm{R}_{3}$ & $\mathrm{Ph}$ & $\mathrm{Me}$ & 2-thienyl & trans-cinnamyl & $\mathrm{Ph}$ \\
$\mathrm{R}_{1}, \mathrm{R}_{2}$ & $\mathrm{Me}, \mathrm{Ph}$ & $\mathrm{Me}, \mathrm{Ph}$ & $\mathrm{Me}, \mathrm{Ph}$ & $\mathrm{Me}, \mathrm{Me}$ & NHCOPh, Ph \\
Solvent & - & $\mathrm{H}_{2} \mathrm{O}$ & - & $\mathrm{H}_{2} \mathrm{O}$ & 1.5(1,4-dioxane) \\
$\mathrm{CSD}[\mathrm{Ref}]$ & DEBFAR02 [12] & XEGVEK [13] & CIQFAJ [14] & HESTOO [15] & MUGQIO [16] \\
$\mathrm{T}(\mathrm{K})$ & 293 & $293(2)$ & 299 & 185 & 293 \\
$\mathrm{O} \ldots \mathrm{O}$ & cis $(\mathbf{C})$ & trans $(\mathbf{D})$ & trans $(\mathbf{D})$ & trans $(\mathbf{D})$ & trans $(\mathbf{D})$ \\
& & & & & \\
Distances $(\AA)$ & & & & & \\
$\mathrm{C} 1-\mathrm{O} 1$ & $1.247(3)$ & $1.257(3)$ & $1.246(2)$ & $1.255(3)$ & $1.222(2)$ \\
$\mathrm{C} 2-\mathrm{O} 2$ & $1.227(3)$ & $1.217(3)$ & $1.230(2)$ & $1.259(3)$ & $1.246(3)$ \\
$\mathrm{O} \ldots \mathrm{O}$ & $3.079(3)$ & - & - & - & - \\
\hline
\end{tabular}

scattering power of the compound. Therefore, we follow a twostep procedure in this study: (I) We present conventional free and restrained refinements of the relevant hydrogen atom positions in the acyl-pyrazolone data sets, either re-refined or taken from the published Crystallographic Information Files (CIFs). We show how problematic routine and common IAM treatments are relative to theoretical geometry optimizations of the hydrogen atom position in question, and highlight how important accurate determination of hydrogen atom positions in tautomers is. (II) We present a further, so far unknown compound (3) with a RAHB that allows the two possible enolic tautomers $\mathbf{A}$ and $\mathbf{B}$ (Scheme 2). A routine low-resolution X-ray data set $(d=0.8 \AA$ ) establishes the non-hydrogen connectivity of $\mathbf{3}$, which is an unexpected new product of a photolysis reaction (see Experimental Part). The hydrogen atom position in the RAHB is then derived from IAM and HAR refinements and compared against theoretical calculations.

\section{Experimental and computational details}

\section{Experimental}

\section{Tautomerism in acyl-pyrazolones}

The data pertinent to this study are already available in the existing literature (Tables 1 and 2). However, for our purposes, which are particularly concerned with the definition of the protonic hydrogen atom locations in the enol forms of the compounds in question, and in the absence of any definitive supporting neutron diffraction studies, we have found it useful to reprocess associated data where they may be available: in some cases from structure factor depositions, in others from our own archives, allowing protonic hydrogen atom coordinates and displacement parameters to refine freely within a SHELXL program [49] using full matrix least squares within the conventional IAM. Details of the updated refinements are given in the Supporting Information.

\section{Tautomerism in a photolysis product}

Observation of a colour change of crystals of the bright yellow quinone $\mathbf{1}$ on exposure to laboratory light triggered further investigation of its photochemical behaviour. Irradiation of $\mathbf{1}$ yields an orange-red compound which was originally formulated as structure $\mathbf{2}$ on the basis of NMR spectroscopy and a mechanistic rationale [50]. But X-ray crystallographic examination (see below) has now established that the photolysis product possesses the title structure 3 (Scheme 3).

The formation of $\mathbf{3}$ can be rationalized through fragmentation of the di- $\pi$-methane [51] intermediate 4, which then undergoes tautomerism to provide 3 (Scheme 4).

In detail, a solution of 1,4-dihydro-1,4-epoxyanthracene-9,10dione 1 [52] (105 mg) in dry deoxygenated dichloromethane $(100 \mathrm{ml})$ was irradiated externally through Pyrex in a chamber reactor equipped with $350 \mathrm{~nm}$ lamps for $1 \mathrm{~h}$. The dark orange-red solution was concentrated to ca. $5 \mathrm{ml}$ and diluted with warm light petroleum (ca. $10 \mathrm{ml}$ ). On cooling, the solution 9-hydroxy-4oxocyclopenta[1,2- $b]$ naphthalene-1-carboxaldehyde $\mathbf{3}$ deposited as orange-red platelets ( $74 \mathrm{mg}$ ) of indefinite melting point. Mass spectrum $m / z, 224$ (M+, 100\%), 139 (46), 119 (15), 84 (28). (Found: $\mathrm{M}+224.0470 . \mathrm{C}_{14} \mathrm{H}_{8} \mathrm{O}_{3}$ requires 224.0473). ${ }^{1} \mathrm{H} \mathrm{NMR}$ $\left(500 \mathrm{MHz}, \mathrm{CDCl}_{3}\right) \delta: 16.82(d, J 5.5 \mathrm{~Hz}, 1 \mathrm{H}, \mathrm{OH}), 9.20(d, J$ $5.5 \mathrm{~Hz}, 1 \mathrm{H}, \mathrm{CHO}), 8.15$ ( $m, 2 \mathrm{H}, \mathrm{H} 5, \mathrm{H} 8), 7.65$ ( $m, 2 \mathrm{H}, \mathrm{H} 6, \mathrm{H} 7)$, $7.32(d, J 3.8 \mathrm{~Hz}, 1 \mathrm{H}, \mathrm{H} 2), 7.15(d, J 3.8 \mathrm{~Hz}, \mathrm{H} 3) .{ }^{13} \mathrm{C} \mathrm{NMR}$ (125.8 MHz, $\mathrm{CDCl}_{3}$ ) $\delta: 183.7$ (CHO), 180.9 (CO), 172.4 (C9), 138.2 (C3), 137.6 (C1), 134.1 (C4a or C8a), 133.9 (C6 or C7), 133.3 (C7 or C6), 132.4 (C8a or C4a), 130.6 (C9a), 127.8 (C5 or C8), 127.1 (C8 or C5), 126.1 (C2), 121.6 (C3).

Crystallographic data for 3 were collected at 150(2) $\mathrm{K}$ on a Bruker SMART CCD diffractometer fitted with graphitemonochromated Mo- $\mathrm{K}_{\alpha}$ radiation. Following multi-scan absorption correction and solution by direct methods with SHELXS [49], the structure was refined against $F^{2}$ up to a resolution of $d=0.8 \AA$ with full-matrix least-squares using the program SHELXL [49] within an IAM. The hydroxyl hydrogen atom was located from the Fourier difference map and refined isotropically without restraints. The remaining hydrogen atoms 
Table 2 Pyrazolone crystal structures in the enol form and selected bond distances ( $\AA$ ) not involving the hydrogen atom in the RAHB because it is not determined accurately (see Fig. 1 for details, and compare to Table 3). Tables with complete geometric details are deposited with the Supporting Information (Table S3)

\begin{tabular}{|c|c|c|c|c|c|}
\hline $\mathrm{R}_{3}$ & 2-furyl (2 mols.) & $\mathrm{p}-\mathrm{C} 6 \mathrm{H} 4-\mathrm{Ph}$ & adamantyl & p-C6H4-Me & Et \\
\hline $\mathrm{R}_{1}, \mathrm{R}_{2}$ & $\mathrm{Me}, \mathrm{Ph}$ & $\mathrm{Me}, \mathrm{Ph}$ & $\mathrm{Me}, \mathrm{Ph}$ & $\mathrm{Me}, \mathrm{Ph}$ & $\mathrm{Me}, \mathrm{Ph}$ \\
\hline CSD [Ref] & ASELEP [17] & ZOJZAB [18] & MELNEX [19] & VIMPAJ [20] & CIQFEN [14] \\
\hline $\mathrm{T}(\mathrm{K})$ & ca 153 & ca 100 & 140 & 293 & 301 \\
\hline \multicolumn{6}{|c|}{ Distances $(\AA)$} \\
\hline C1-O1 & $1.285(2), 1.284(2)$ & $1.2924(13)$ & $1.325(3)$ & $1.307(3)$ & $1.3132(14)$ \\
\hline $\mathrm{C} 2-\mathrm{O} 2$ & $1.306(2), 1.310(2)$ & $1.2826(13)$ & $1.256(3)$ & $1.268(3)$ & $1.256(2)$ \\
\hline $\mathrm{O} \ldots \mathrm{O}$ & $2.450(2), 2.460(2)$ & $2.4800(13)$ & $2.515(2)$ & $2.527(2)$ & $2.5327(14)$ \\
\hline $\mathrm{R}_{3}$ & Me (2 mols. $)$ & p-C6H4-NMe2 & trans-PhCH:CH & nor-bornyl & $\mathrm{n}-\mathrm{Pr}$ \\
\hline $\mathrm{R}_{1}, \mathrm{R}_{2}$ & $\mathrm{Me}, \mathrm{Ph}$ & $\mathrm{Me}, \mathrm{Ph}$ & $\mathrm{Me}, \mathrm{Ph}$ & $\mathrm{Me}, \mathrm{Ph}$ & $\mathrm{Me}, \mathrm{Ph}$ \\
\hline CSD [Ref] & ADURIA01 [22] & RAXXUK [23] & CIQDUB [14] & ASUPUA [24] & LELDIP [25] \\
\hline $\mathrm{T}(\mathrm{K})$ & $296(2)$ & $298(2)$ & 297 & $150(2)$ & 295 \\
\hline \multicolumn{6}{|c|}{ Distances $(\AA)$} \\
\hline $\mathrm{C} 1-\mathrm{O} 1$ & $1.290(3), 1.284(3)$ & $1.287(2)$ & $1.261(2)$ & $1.318(2)$ & $1.319(6)$ \\
\hline $\mathrm{C} 2-\mathrm{O} 2$ & $1.275(3), 1.283(4)$ & $1.306(3)$ & $1.312(2)$ & $1.253(2)$ & $1.256(6)$ \\
\hline $\mathrm{O} \ldots \mathrm{O}$ & $2.543(2), 2.527(3)$ & $2.529(2)$ & $2.558(2)$ & $2.569(2)$ & $2.583(5)$ \\
\hline $\mathrm{R}_{3}$ & $\mathrm{Me}(\mathrm{C} 2 / \mathrm{c})$ & CH:CMeOH (2 mols.) & $\mathrm{Ph}(2$ mols. $)$ & $\begin{array}{l}{\left[4-\left\{\left(\mathrm{CH}_{2}\right)_{4}\right\}\right.} \\
\quad(1,3-\mathrm{Ph}, \mathrm{MepzH})]\end{array}$ & trans-PhCH:CH \\
\hline $\mathrm{R}_{1}, \mathrm{R}_{2}$ & $\mathrm{Me}, \mathrm{Ph}$ & $\mathrm{Me}, \mathrm{Ph}$ & $\mathrm{Me}, \mathrm{Ph}$ & $\mathrm{Me}, \mathrm{Ph}$ & $\mathrm{Me}, \mathrm{Me}$ \\
\hline CSD [Ref] & ADURIA [21] & DEBFEV [26] & YUYDOL [12] & ULUFOX [27] & HESTUU [15] \\
\hline $\mathrm{T}(\mathrm{K})$ & ca 295 & 193 & $296(1)$ & ca 153 & 185 \\
\hline \multicolumn{6}{|c|}{ Distances $(\AA)$} \\
\hline $\mathrm{C} 1-\mathrm{O} 1$ & $1.315(2)$ & $1.329(4), 1.334(4)$ & $1.324(3), 1.323(3)$ & $1.3249(8)$ & $1.317(3)$ \\
\hline $\mathrm{C} 2-\mathrm{O} 2$ & $1.237(3)$ & $1.281(4), 1.279(4)$ & $1.247(3), 1.243(3)$ & $1.2421(9)$ & $1.273(3)$ \\
\hline $\mathrm{O} \ldots \mathrm{O}$ & $2.592(3)$ & $2.627(2), 2.633(2)$ & $2.663(2), 2.621(3)$ & $2.6941(7)$ & $2.585(3)$ \\
\hline $\mathrm{R}_{3}$ & 2-thienyl & 2-furyl & & & \\
\hline $\mathrm{R}_{1}, \mathrm{R}_{2}$ & $p-\mathrm{C}_{6} \mathrm{H}_{4}-\mathrm{Cl}, \mathrm{Ph}$ & $p-\mathrm{C}_{6} \mathrm{H}_{4}-\mathrm{Cl}, 2$-fur & & & \\
\hline CSD [Ref] & PAXWUI [28] & DEYSIK [29] & & & \\
\hline $\mathrm{T}(\mathrm{K})$ & 296 & 295 & & & \\
\hline \multicolumn{6}{|c|}{ Distances $(\AA)$} \\
\hline C1-O1 & $1.323(2)$ & $1.322(2)$ & & & \\
\hline $\mathrm{C} 2-\mathrm{O} 2$ & $1.239(2)$ & $1.234(2)$ & & & \\
\hline $\mathrm{O} \ldots \mathrm{O}$ & $2.724(2)$ & $2.857(2)$ & & & \\
\hline
\end{tabular}

were added at calculated positions and refined by use of a riding model with isotropic displacement parameters based on that of the parent atom. Anisotropic displacement parameters (ADPs) were employed for all non-hydrogen atoms. Subsequently, HAR was carried out using the program Tonto version 3.2.0 [43]. Point charges and dipoles were placed at atomic positions of all symmetry-generated molecules for which at least one atom was within an $8 \AA$ radius of any atom of the asymmetric unit in order to polarize the central molecule and simulate the crystal effect. It has been shown that external polarization of the molecule through a simulated crystal field yields more accurate hydrogen atom positions [43]. For the repetitive tailor-made generation of aspherical scattering factors, according to Hirshfeld's stockholder partitioning of the quantum-mechanical electron density [53, 54], the BLYP/cc-pVTZ level of theory was used. Positions of all hydrogen atoms were freely refined. Two models were obtained: one with isotropic displacement parameters of hydrogen atoms (HAR iso) and one with ADPs for hydrogen atoms 
Scheme 2 Tautomers $\mathbf{A}$ and $\mathbf{B}$ of 9-hydroxy-4-oxocyclopenta[1,2b]naphthalene-1-carboxaldehyde (3)

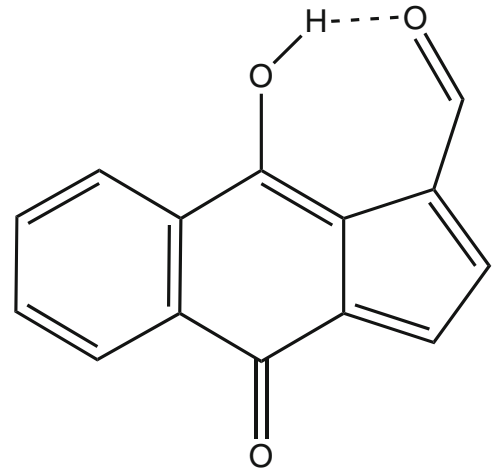

3A<smiles>O=C1C2=C3C(=CO[CH]O[C@H]13)C=C2</smiles>

3B
(HAR_aniso). Pertinent details are listed in the Supporting Information (Table S1). The corresponding CIFs are deposited with the Cambridge Structural Database under nos. CCDC1535277 to 1535279 (IAM, HAR_iso, HAR aniso, respectively) and can be downloaded free of charge under https://summary. ccdc.cam.ac.uk/structure-summary. The Tonto program and its subprogram HARt that carries out Hirshfeld atom refinements can be downloaded free of charge from https://github.com/ dylan-jayatilaka/tonto. The input files for the HAR treatments of 3 have been deposited within the CIFs as supporting information of this paper. Alternatively, HAR is part of the crystallographic program Olex2 (http://www.olexsys.org/).

\section{Theoretical}

\section{Tautomerism in acyl-pyrazolones}

Isolated-molecule geometry optimizations were carried out for a representative set of both keto and enol tautomersXEGVEK, ADURIA, ASELEP, CIQFAJ, DEBFAR02, VIMPAJ - with the program Gaussian09 [55] using the B3LYP/6-31+G(2df,p) level of theory. Frequency calculations were performed in order to ensure that the structures were minima on the potential energy surface, which is the case for all structures discussed in this study. For all compounds, three different potential energy minima were obtained that correspond to the forms $\mathbf{A}, \mathbf{B}$ and $\mathbf{D}$. $\mathbf{C}$ is not a minimum on the potential energy surface in the isolated state.

\section{Tautomerism in a photolysis product}

For title compound 3, isolated-molecule geometry optimizations with Gaussian09 were carried out using two different levels of theory, namely B3LYP/6-31+G(2df,p) to be consistent with the calculations in Part I and B3LYP/cc-pVTZ to be consistent with the HAR results on $\mathbf{3}$. All obtained geometries are minima on the potential energy surface confirmed through frequency analyses, and minima were found for both tautomers 3A and 3B (Scheme 2). Subsequent natural-bond orbital analyses with the program NBO6.0 [56] yielded natural population analysis (NPA) charges and natural localized molecular orbital (NLMO) bond orders. Deformation density maps after HAR result from a singlepoint calculation at the BLYP/ cc-pVTZ level within Tonto and are plotted using XDGRAPH [57]. Hirshfeld surface analyses were carried out with the program CrystalExplorer [58]. In addition, a transition state search was performed for compound 3 at B3LYP/6-31+ $\mathrm{G}(2 \mathrm{df}, \mathrm{p})$ level starting from a geometry with the proton being located midway between the two oxygen atoms. A frequency analysis confirmed that the saddle point obtained was indeed related to the proton transfer. Another additional geometry optimization at the same level of theory started from a dimer

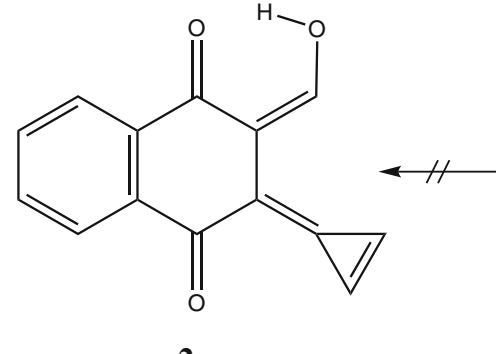

2<smiles>O=CC1=CC=C2C(=O)c3ccccc3C(O)=C12</smiles>

1

Scheme 3 Possible photolysis products of quinone $\mathbf{1}$ 


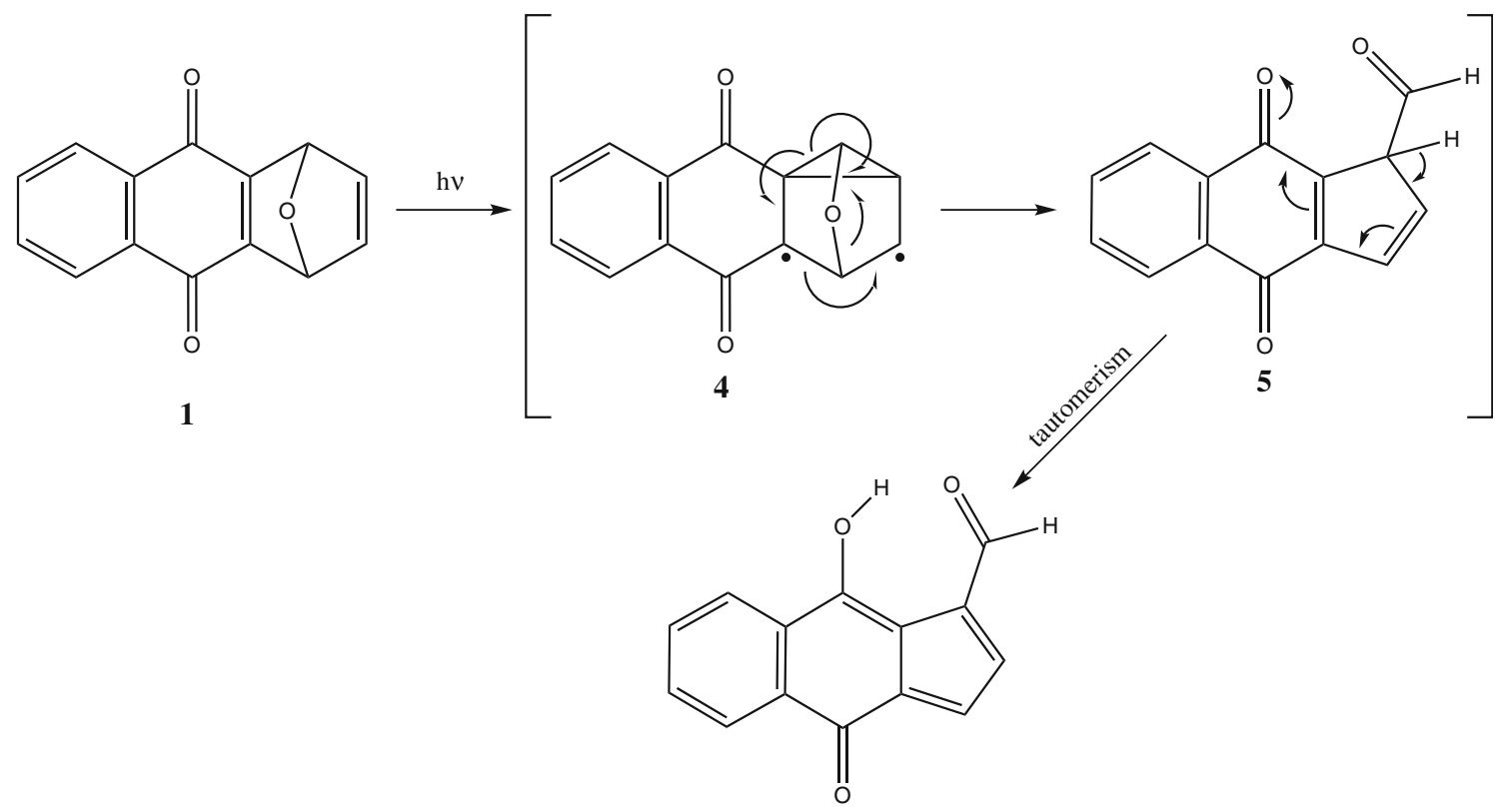

3

Scheme 4 Likely reaction mechanism of the photolysis of 1 leading to 9-hydroxy-4-oxocyclopenta[1,2-b]naphthalene-1-carboxaldehyde (3) involving a tautomerism step

as extracted from the crystal packing of 3 that included the $\mathrm{C} 3$ H3...O10 hydrogen bond.

\section{Results and discussion}

\section{Tautomerism in acyl-pyrazolones}

Addressing the more limited number of examples of the keto form first, in which the nitrogen atom is protonated (Table 1), we find that there is only one example of the $\mathbf{C}$ form in which the pair of keto groups are cis (DEBFAR [12, 26, 59]), the remainder being D (trans) (XEGVEK [13], CIQFAJ [14], HESTOO [15], MUGQIO [16]) (Table 1). Indeed, why DEBFAR should be cis rather than the more abundant trans keto form is presumably a consequence of the imposition of lattice forces on a pair of systems of comparable energy, among which a hydrogen bond to the acyl-oxygen atom intermolecularly from a protonated nitrogen atom may be noted. All other $\mathrm{O}$...H contacts exceed $2.5 \AA$, and, intramolecularly, $\mathrm{O}$...O (3.079(3) $\AA$ ) is long, with the pendant acyl group twisted appreciably out-of-plane (more details in the Supporting Information, Table S2).

In the D-type (trans) examples, the core dimensions of the $\mathrm{R}_{1}, \mathrm{R}_{2}=\mathrm{Me}, \mathrm{Ph}$ compounds (XEGVEK [13], CIQFAJ [14]) are very similar, and also very similar to those of the cis DEBFAR [12, 26, 59] example (Table S2). Notwithstanding intermolecular hydrogen approaches to the diketone oxygen atoms by a pair of symmetry-related cocrystallized water molecules at $\mathrm{H} \ldots \mathrm{O}=1.92(5), 1.98(4) \AA$ in the former (XEGVEK [13]), these suggest a useful common baseline set of core dimensions for the keto forms. The core dimensions in HESTOO [15] and MUGQIO [16] are different to those of the $\mathrm{R}_{1}, \mathrm{R}_{2}=\mathrm{Me}, \mathrm{Ph}$ forms by about 5 to 10 standard uncertainties (Table S2), caused by the different substitution pattern. However, all compounds in the keto form have a moderately strong [60] interspecies $\mathrm{N}-\mathrm{H} . . . \mathrm{O}$ hydrogen bond in common that can be as short as H...O = 1.82(2) $\AA$ in CIQFAJ [14]. (Intermolecular interactions are discussed in the footnote of Table S2). Since in the gas phase the keto form is always energetically less favourable (Table 3 ) in a range from 21.7 to $55.9 \mathrm{~kJ} / \mathrm{mol}$ relative to the more stable of the two enol forms, the discussed moderately strong $\mathrm{N}-\mathrm{H}$... O hydrogen bonds are likely to be the reason for the existence of the keto form in the crystalline state. The dissociation energy of a single moderately strong hydrogen bond lies in the range from ca. 15 to $65 \mathrm{~kJ} / \mathrm{mol}$ [60], not counting any other electrostatic and dispersion energy components of a close dimeric contact that will add energetically to the directed atom-atom interaction. In the keto form, both bonds $\mathrm{C} 1-\mathrm{O} 1$ and $\mathrm{C} 2-\mathrm{O} 2$ are associated with double-bond character (Scheme 1), which can be confirmed by the $\mathrm{C}-\mathrm{O}$ bond distances given in Table 1 .

Turning to the enol forms A, B (Table 2), which are significantly more numerous than the keto forms, the $\mathrm{C}-\mathrm{O}$ dispositions are invariably cis. Across this array of $\mathrm{R}_{1}, \mathrm{R}_{2}=\mathrm{Me}, \mathrm{Ph}$ substituted compounds (determined at a diversity of temperatures and arranged in order of increasing $\mathrm{O}$... O distance in Table 2), the O...O distances range from 2.450(2) (ASELEP 
Table 3 Relative energies of tautomer forms $\mathbf{A}, \mathbf{B}, \mathbf{D}$ and selected optimized bond distances $(\AA)$, including the bonds that involve the mobile hydrogen atom in question. The CSD REFCODEs serve as orientation about the compound that was used as a starting point for the calculations. In fact, the hydrogen atom was placed at all three possible positions yielding all optimized tautomer forms $\mathbf{A}, \mathbf{B}$,

D. Geometric details are given in Tables S4 and S5

\begin{tabular}{|c|c|c|c|c|c|c|}
\hline \multicolumn{2}{|l|}{$\mathrm{R}_{3}$} & $\mathrm{Ph}$ & 2-furyl & $\mathrm{Me}$ & 2-thienyl & $p$-tolyl \\
\hline \multicolumn{2}{|l|}{$\mathrm{R}_{1,2}$} & $\mathrm{Ph}, \mathrm{Me}$ & $\mathrm{Ph}, \mathrm{Me}$ & $\mathrm{Ph}, \mathrm{Me}$ & $\mathrm{Ph}, \mathrm{Me}$ & $\mathrm{Ph}, \mathrm{Me}$ \\
\hline \multicolumn{2}{|l|}{ CSD } & DEBFAR02 & ASELEP & ADURIA & CIQFAJ & VIMPAJ \\
\hline \multicolumn{7}{|c|}{ Rel. E (kJ/mol) } \\
\hline \multicolumn{2}{|c|}{$\mathrm{E}(\mathbf{A})$} & 1.50 & 0.00 & 2.29 & 1.28 & 0.93 \\
\hline \multicolumn{2}{|l|}{$\mathrm{E}(\mathbf{B})$} & 0.00 & 0.04 & 0.00 & 0.00 & 0.00 \\
\hline \multicolumn{2}{|l|}{$\mathrm{E}(\mathbf{D})$} & 55.95 & 55.34 & 31.24 & 21.71 & 34.76 \\
\hline \multirow[t]{3}{*}{$\mathrm{C} 1-\mathrm{O} 1$} & $\mathbf{A}$ & 1.250 & 1.252 & 1.248 & 1.252 & 1.250 \\
\hline & B & 1.318 & 1.314 & 1.320 & 1.317 & 1.318 \\
\hline & D & 1.216 & 1.221 & 1.225 & 1.234 & 1.229 \\
\hline \multirow[t]{3}{*}{$\mathrm{C} 2-\mathrm{O} 2$} & $\mathbf{A}$ & 1.321 & 1.324 & 1.319 & 1.323 & 1.321 \\
\hline & B & 1.251 & 1.259 & 1.246 & 1.255 & 1.252 \\
\hline & D & 1.216 & 1.221 & 1.225 & 1.234 & 1.229 \\
\hline \multirow[t]{3}{*}{$\mathrm{O} 1-\mathrm{O} 2$} & $\mathbf{A}$ & 2.528 & 2.454 & 2.552 & 2.490 & 2.526 \\
\hline & B & 2.554 & 2.501 & 2.588 & 2.528 & 2.550 \\
\hline & D & 3.266 & 3.171 & $(4.382)$ & $(4.448)$ & $(4.353)$ \\
\hline \multirow[t]{3}{*}{$\mathrm{O} 1-\mathrm{H}$} & $\mathbf{A}$ & 1.580 & 1.535 & 1.613 & 1.528 & 1.578 \\
\hline & B & 1.008 & 1.017 & 1.004 & 1.011 & 1.009 \\
\hline & D & - & - & - & - & - \\
\hline \multirow[t]{3}{*}{$\mathrm{O} 2-\mathrm{H}$} & $\mathbf{A}$ & 1.018 & 1.023 & 1.014 & 1.025 & 1.018 \\
\hline & B & 1.643 & 1.570 & 1.686 & 1.612 & 1.637 \\
\hline & D & - & - & - & - & - \\
\hline \multirow[t]{3}{*}{ O1-H-O2 } & $\mathbf{A}$ & 152.63 & 153.82 & 151.83 & 154.04 & 152.75 \\
\hline & B & 147.86 & 149.56 & 147.15 & 148.27 & 148.05 \\
\hline & D & - & - & - & - & - \\
\hline \multirow[t]{3}{*}{$\mathrm{N}-\mathrm{H}$} & $\mathbf{A}$ & - & - & - & - & - \\
\hline & B & - & - & - & - & - \\
\hline & D & 1.016 & 1.016 & 1.014 & 1.014 & 1.014 \\
\hline
\end{tabular}

[17]) to 2.6941(7) $\AA$ (ULUFOX [27]). The acyl out-of-plane torsion is less than 30 degrees across the whole spectrum. All geometric details are listed in the Supporting Information, Table S3.

For the assignment of the two distinct tautomers $\mathbf{A}$ and $\mathbf{B}$, depending on which of the pair of adjacent oxygen atoms are considered to be protonated, the hydrogen atom position must be identified unambiguously, which can be difficult if solely based on X-ray data as discussed in the "Introduction" section. However, forms $\mathbf{A}$ and $\mathbf{B}$ entail different formal bonding schemes in respect of the pair of potential carbonyl groups and their environment (see Scheme 1), constituting the resonance system that is bridged/closed by the RAHB, the remainder of the molecule remaining essentially constant. For those compounds with the longest $\mathrm{O} \ldots \mathrm{O}$ distances, the hydrogen atom freely refined using the IAM seems to be located in association with the fused ring carbonyl oxygen atom $\mathrm{O} 1$, which also has one of the longest fused C1-O1 distances (ULUFOX, 1.3249(8) $\AA$ ) indicating single-bond character relative to C2$\mathrm{O} 2(d=1.2421(9) \AA)$ that shows double-bond character (type
B). ADURIA is another example of type B (Fig. 1b), but here the $\mathrm{O}-\mathrm{H}$ distance was not freely refined, but fixed within a riding model. Hence, the categorization can only be based on the non- $\mathrm{H}$ bond distances, which is unambiguous in this case (C1-O1 a single bond, $\mathrm{C} 2-\mathrm{O} 2$ a double bond and the $\mathrm{C}-\mathrm{C}$ bonds alternating single and double bonds), so the hydrogen atom must be associated with $\mathrm{O} 1$ relatively closely. This is confirmed by the theoretical geometry optimizations (second line in Fig. 1b, Table 3). The O1-H distance in ADURIA was calculated to be $1.004 \AA$, and the alternating single- and double-bond pattern is confirmed. This also means that the hydrogen bond is not strictly a RAHB anymore, as expected with a $\mathrm{O} . . . \mathrm{O}$ distance above $2.5 \AA$.

For the compound with the shortest $\mathrm{O} \ldots \mathrm{O}$ distances (ASELEP, $2 \mathrm{~mol} ; 2.450,2.460(2) \AA$ ), the hydrogen atom locations move a bit closer to the acyl carbonyl oxygen atom $\mathrm{O} 2$ - also true of the compound with the next shortest $\mathrm{O} \ldots \mathrm{O}$ distance (ZOJZAB, 2.4800(13) $\AA$ ) -although the O2-H distance is still shorter than the O1-H distance which would still indicate type B (Fig. 1a). However, the non-hydrogen 
ASELEP (mol. 1) (type A)

$$
\mathrm{O} \ldots \mathrm{O} 2.450(2) \AA
$$

$2.454 \AA$

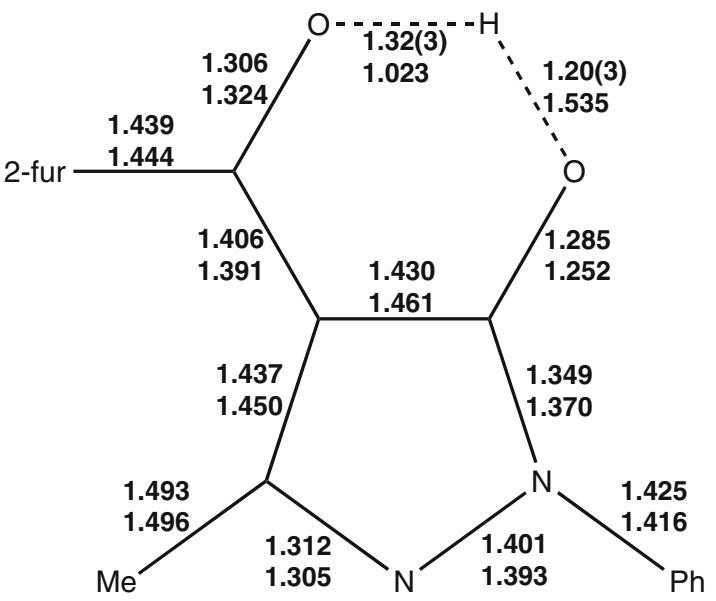

(a) experimental s.u.'s (non-H): Distances $0.002 \AA$

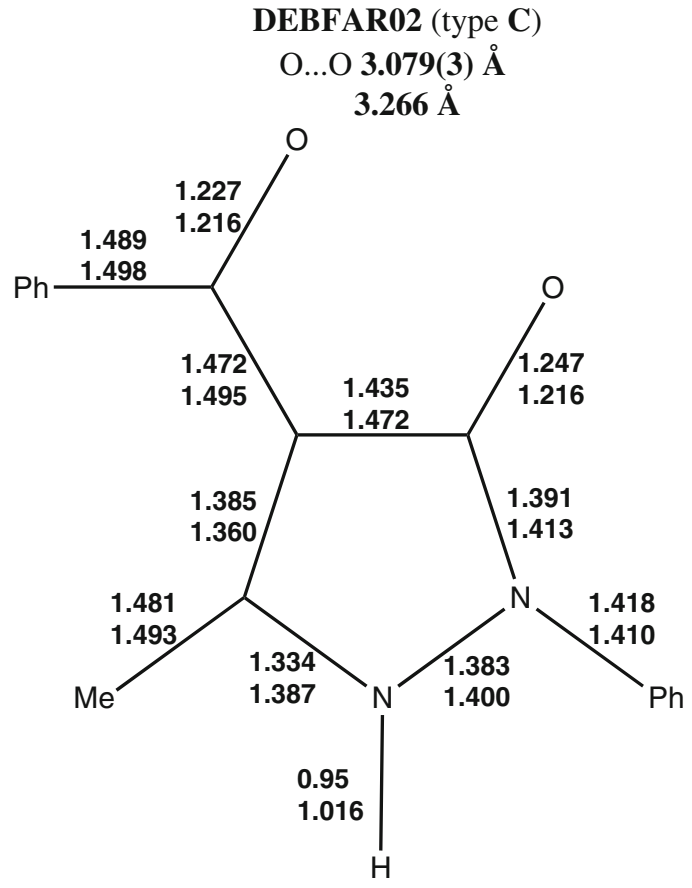

(c) experimental s.u.'s (non-H): Distances $0.003 \AA$

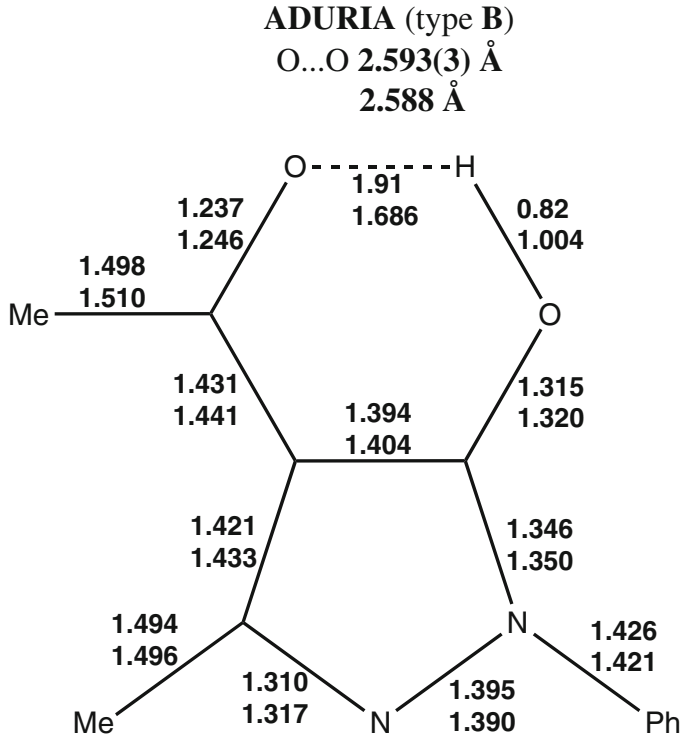

(b) experimental s.u.'s (non-H):

Distances $0.003 \AA$

XEGVEK (type D)

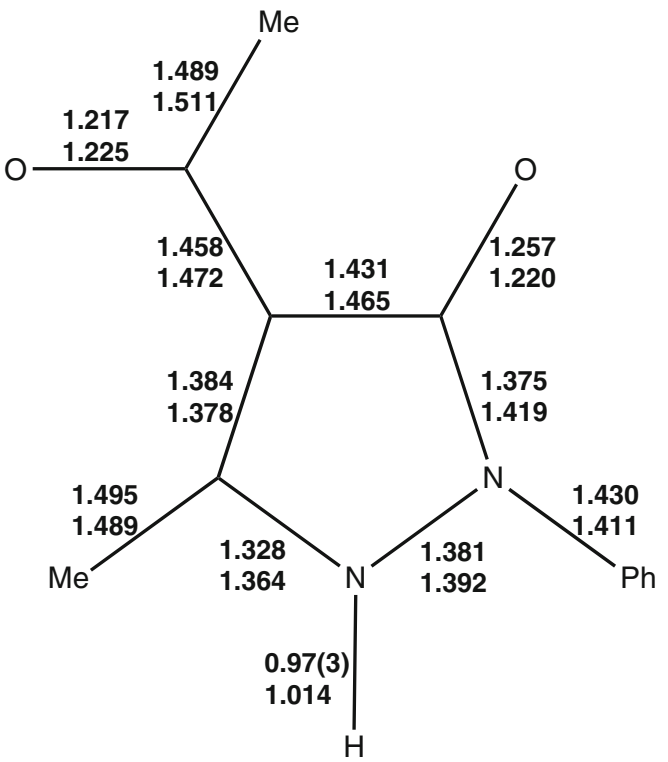

(d) experimental s.u.'s (non-H): Distances $0.003 \AA$

Fig. 1 Experimental (first line) and theoretical (second line) bond distances $(\AA)$ for examples of the four possible tautomers $\mathbf{A}-\mathbf{D}$ (a-d)

geometry suggests type $\mathbf{A}$, with $\mathrm{C} 2-\mathrm{O} 2$ being longer than $\mathrm{C} 1$ $\mathrm{O} 1$, and the two $\mathrm{C}-\mathrm{C}$ bonds also showing bond distances with a trend concerning single- and double-bond character opposite to the trend observed for ADURIA, Fig. 1b. However, the pairs of $\mathrm{C}-\mathrm{O}$ and $\mathrm{C}-\mathrm{C}$ bond distances are more similar to each other than in ADURIA, so that the intramolecular hydrogen bond can be considered a RAHB, as expected with a O...O distance below $2.5 \AA$. Figure $1 \mathrm{c}, \mathrm{d}$ for the keto forms show how similar or different the two double-bond $\mathrm{C}=\mathrm{O}$ and singlebond $\mathrm{C}-\mathrm{C}$ distances are when one of the $\mathrm{C}-\mathrm{C}$ bonds is 
incorporated into a resonance system $(\mathrm{C} 1-\mathrm{C})$ and the other one is not $(\mathrm{C} 2-\mathrm{C})$. The theoretical geometry optimizations even out these differences to a considerable extent compared to the experiment, where the differences are more pronounced.

Concerning the identification of types $\mathbf{A}$ and $\mathbf{B}$, the hydrogen atoms as located within the X-ray data sets cannot distinguish between them. Figure 1a, b only pose two examples, the first being a free IAM refinement that fails (ASELEP), and the second a geometric placement that is inconclusive (ADURIA). For the whole variety of attempted localizations of the hydrogen atom in the intramolecular hydrogen bond across the arrays of compounds in Table 2, we refer to Table S3 in the Supporting Information. The non-hydrogen geometries agree largely between experiment and theory within each form $\mathbf{A}$ or $\mathbf{B}$ (Fig. 1, Tables 2 and 3, Tables S2 to S5). However, since a minimum on the potential energy surface is found for each of the two forms, and since form B is slightly more stable (up to $2.3 \mathrm{~kJ} / \mathrm{mol}$, Table 3 ), the isolatedmolecule calculations are not helpful in assigning the tautomer forms in the crystal structures. In DFT, energy differences of 1$2 \mathrm{~kJ} / \mathrm{mol}$ are not significant [61]. Obviously, two advancements must be considered: (i) replacing the IAM with an aspherical Xray refinement model, and (ii) replacing the isolated-molecule calculations with periodic-boundary calculations. In Part II of this study, we will use Hirshfeld atom refinement that combines both ideas: aspherical atom refinement within a simulated theoretical crystal environment.

If for all theoretically investigated compounds in all substitution patterns form $\mathbf{B}$ is more stable by ca. $1-2 \mathrm{~kJ} / \mathrm{mol}$ (Table 3), the electronic effect within the six-membered resonance system is weak, and can easily be overcompensated by the intermolecular interaction pattern. In other words, the crystal packing must be responsible for the occurrence of either type $\mathbf{A}$ or type $\mathbf{B}$ in the crystal structures, as it was identified to be responsible for the existence of the keto forms (see above) that are energetically much more unfavourable compared to the relative difference in energy between tautomers $\mathbf{A}$ and $\mathbf{B}$ in the isolated theoretical case. It was found in a previous study on RAHB containing systems (hydrogen maleate salts) that the hydrogen atom is always placed more closely to that oxygen atom that is less heavily involved in additional intermolecular hydrogen bonds [33]. However, the acylpyrazolone compounds in the enol form (Table 2) lack hydrogen-bonding donors. (For a discussion of intermolecular interactions, see the footnote of Table S3). Therefore, the finding of the hydrogen maleate study cannot easily be verified by scrutiny of the crystal packing of the compounds discussed in this study. Consequently, this point is investigated more closely using Hirshfeld surface analysis in Part II. In addition, it also seems as if the $\mathrm{O}-\mathrm{H}$ bonds are significantly elongated based on the experimental results (mainly judged by the extent of resonance expressed in the non-hydrogen geometry) in comparison to the isolated-molecule calculations, which must also be caused by the intermolecular interactions involving atoms $\mathrm{O} 1$ and $\mathrm{O} 2$. This will be discussed quantitatively in Part II below.

\section{Tautomerism in a photolysis product}

The compound 9-hydroxy-4-oxocyclopenta[1,2-b]naphthalene-1-carboxaldehyde (3) is a hitherto unknown compound that we synthesized in this study according to the description in the "Experimental" section. It contains an intramolecular hydrogen bond with an $\mathrm{O}$... O distance of $2.50 \AA$, so it can be considered a borderline case of a low-barrier hydrogen bond. As for the acyl-pyrazolone compounds in Part I, two tautomers $\mathbf{A}$ and $\mathbf{B}$ are possible (Scheme 2), and the structure itself does not suggest which one might be energetically favoured. The experimental geometry after a HAR with isotropic hydrogen atom treatment is shown in Fig. 2. Anisotropic treatment of hydrogen atom displacement parameters led to a structure

Fig. 2 Experimental structure of 3 after HAR iso (corresponding to $\mathbf{3 A}$, Scheme 2) with atomic displacement parameters plotted at a $50 \%$ probability level and with the atomic numbering scheme used throughout

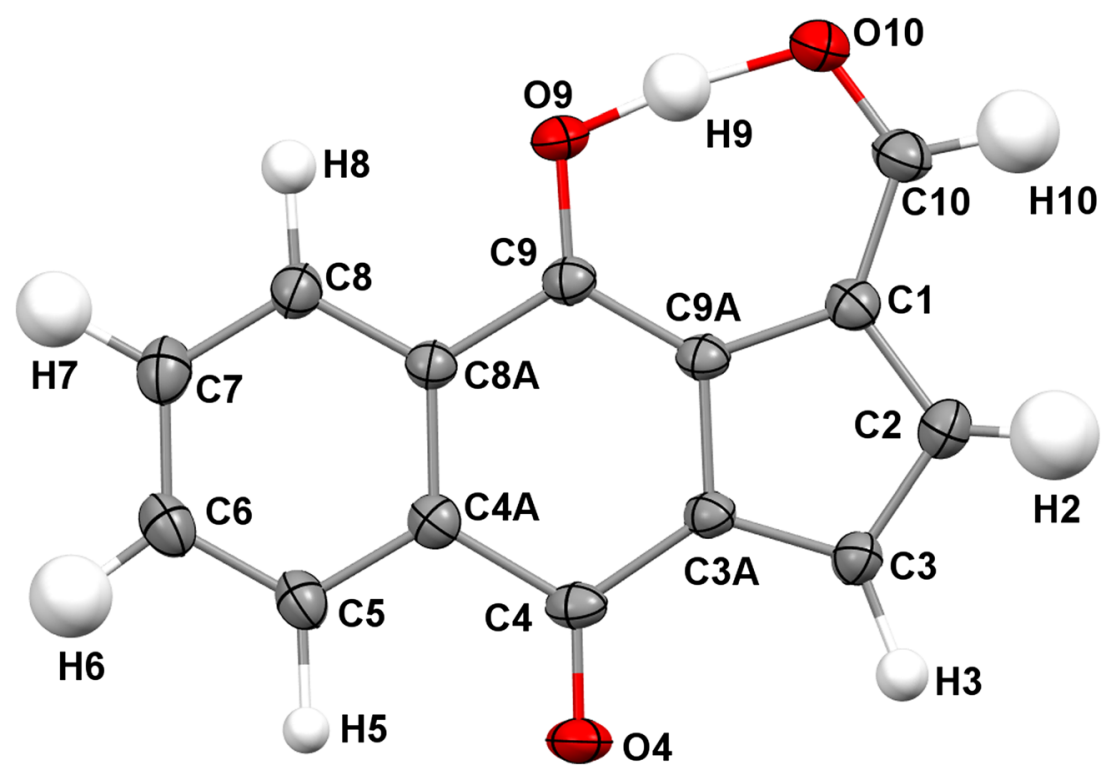


with four non-positive definite hydrogen ADPs, one of which is the hydrogen atom in the intramolecular hydrogen bond, and the remaining ones are flat. We have shown in previous studies that the corresponding A-H bond lengths are nevertheless accurate, maybe even more accurate than those from refinements with isotropic displacement parameters or preestimated and fixed hydrogen ADPs [45]. However, this was criticized recently [38], and our previous investigations were based on high-quality high-order data [44, 45]. With routine data like the ones used here (maximum resolution limit $0.8 \AA$ ), the hydrogen ADP quality reduces so much that we derive all properties discussed later from the HAR_iso model. The IAM model (isotropic hydrogen atoms) is presented in Table 4 for comparison.

The O-H and non-hydrogen distances shown in Table 4 (Tables S6 and S7 for the complete geometry) as well as the refinement statistics ( $R$ value in Table 4 , pertinent details in Table S1) are virtually identical between the HAR_iso and HAR_aniso models. This shows that the unphysical hydrogen ADPs in the HAR_aniso model do not deteriorate the quality of the geometry - the precision is also nearly identical between HAR_iso and HAR_aniso. In contrast to the discussed acyl-pyrazolone refinements in Fig. 1, free IAM modelling succeeds for compound $\mathbf{3}$, which can be judged by the agreement of the O9-H distance with the HAR results within a single standard uncertainty. However, without HAR treatments as reference, it could not have been concluded whether the O9-H distance from the IAM is meaningful or not, which was strikingly exemplified in Part I. In summary, the experimental findings confirm that tautomer $\mathbf{3 A}$ exists in the crystal structure, but with a significantly elongated $\mathrm{O} 9-\mathrm{H}$ distance in line with a RAHB situation.

The difference between the refinement schemes HAR and IAM can be visualized by a map of the static deformation density (Fig. 3). It is basically the difference between the electron densities underlying the two refinement schemes, highlighting the valence electron density distribution that is accounted for in HAR, but not in IAM. From a chemical point of view, it is interesting to note the differences in the shape and orientation of the two lone electron pairs at the oxygen atoms O9 and $\mathrm{O} 10$ in the intramolecular hydrogen bond that are asymmetrically deformed towards each other, and the lone pairs at oxygen $\mathrm{O} 4$ that are highly symmetrical and not involved in strong hydrogen bonding, only in a distant C-H...O interaction (see Tables S8 to S10 for details on the intermolecular interaction pattern).

The isolated-molecule geometry optimizations, first part of Table 4 , show that $\mathbf{3 A}$ is energetically more stable, but by only 2.2 to $2.6 \mathrm{~kJ} / \mathrm{mol}$, depending on the basis set used. The differences in the energetic and geometrical results stemming from the two different basis sets are not significant, so that derived properties (e.g. Fig. 5 below) are based only on the basis set 6 $31+\mathrm{G}(2 \mathrm{df}, \mathrm{p})$ that was also used for the calculations in Part I. A saddle point search identifies geometry 3TS (Table 4) as the transition state of the proton transfer. The energy barrier for the transition relative to $\mathbf{3 A}$ is only $5.56 \mathrm{~kJ} / \mathrm{mol}$. In the transition state, the proton is already by $0.03 \AA$ closer to atom $\mathrm{O} 10$ than to $\mathrm{O} 9$, and the $\mathrm{O}$... O distance is shortened by $0.1 \AA$ compared to $\mathbf{3 A}$. The $\mathrm{O} 9-\mathrm{H}$ distance in type $\mathbf{3 A}$ based on the geometry optimization is significantly shorter than the experimental value. Correspondingly, the C9-O9 and C10-O10 distances are slightly more similar to each other in the experiment than in theory for type $\mathbf{3 A}$. Hence, the intrinsic charge separation and resonance described in the isolated-molecule calculations do not fully recover the shift of the hydrogen atom from $\mathrm{O} 9$ towards $\mathrm{O} 10$ found in the experimental structure (i.e. $1.03 \AA$ (theo) vs. $1.15 \AA$ (exp)). Cooperative effects in the crystalline environment strengthen the intramolecular hydrogen bond, and shorten the O...O distance (i.e. $2.53 \AA$ (theo) vs. $2.49 \AA$ (exp)). This finding was already anticipated in Part I., and can be confirmed here. Since the energy differences between types $\mathbf{3 A}$ and $\mathbf{3 B}$ are as small as in Part I for the acyl-pyrazolones, the

Table 4 Relative energies of tautomer forms $\mathbf{A}$ and $\mathbf{B}$, as well as selected bond distances $(\AA)$ and angles $\left({ }^{\circ}\right)$ from geometry optimization at B3LYP level (basis set, see entries in this table) and from experiment, including the bonds that involve the mobile hydrogen atom in question

\begin{tabular}{|c|c|c|c|c|c|c|c|}
\hline & $\mathrm{O} 9-\mathrm{H}$ & $\mathrm{O} 10-\mathrm{H}$ & O9...O10 & C9-O9 & $\mathrm{C} 10-\mathrm{O} 10$ & O9-H-O10 & \\
\hline Theory: & & & & & & & Rel. E (kJ/mol) \\
\hline $\mathbf{3 A}(\mathrm{cc}-\mathrm{pVTZ})$ & 1.030 & 1.511 & 2.533 & 1.304 & 1.241 & 170.89 & 0 \\
\hline $3 B$ & 1.494 & 1.035 & 2.521 & 1.249 & 1.295 & 170.24 & 2.22 \\
\hline $\mathbf{3 A}(6-31+\mathrm{G}(2 \mathrm{df}, \mathrm{p}))$ & 1.033 & 1.502 & 2.527 & 1.305 & 1.244 & 170.72 & 0 \\
\hline $3 B$ & 1.478 & 1.042 & 2.511 & 1.253 & 1.296 & 170.27 & 2.56 \\
\hline $3 T S$ & 1.222 & 1.192 & 2.410 & 1.274 & 1.271 & 173.50 & 5.56 \\
\hline 3Dimer & 1.037 & 1.486 & 2.517 & 1.305 & 1.249 & 171.24 & $\mathrm{~N} / \mathrm{A}$ \\
\hline Experiment: & & & & & & & $R$ value \\
\hline IAM & $1.11(3)$ & $1.39(3)$ & $2.496(2)$ & $1.301(3)$ & $1.248(3)$ & $174(3)$ & 0.0457 \\
\hline HAR_iso & $1.15(4)$ & $1.35(4)$ & $2.496(3)$ & $1.293(3)$ & $1.245(4)$ & $171(3)$ & 0.0424 \\
\hline HAR_aniso & $1.14(4)$ & $1.36(4)$ & $2.499(3)$ & $1.296(3)$ & $1.247(4)$ & $172(3)$ & 0.0423 \\
\hline
\end{tabular}


Fig. 3 Theoretical static deformation density map based on the HAR_iso geometry. It depicts the difference between the electron density distributions underlying the IAM and the HAR. Bonds and lone pair regions are pronounced in the HAR, which agrees more favourably with the experimental structure factors and leads to improved geometry

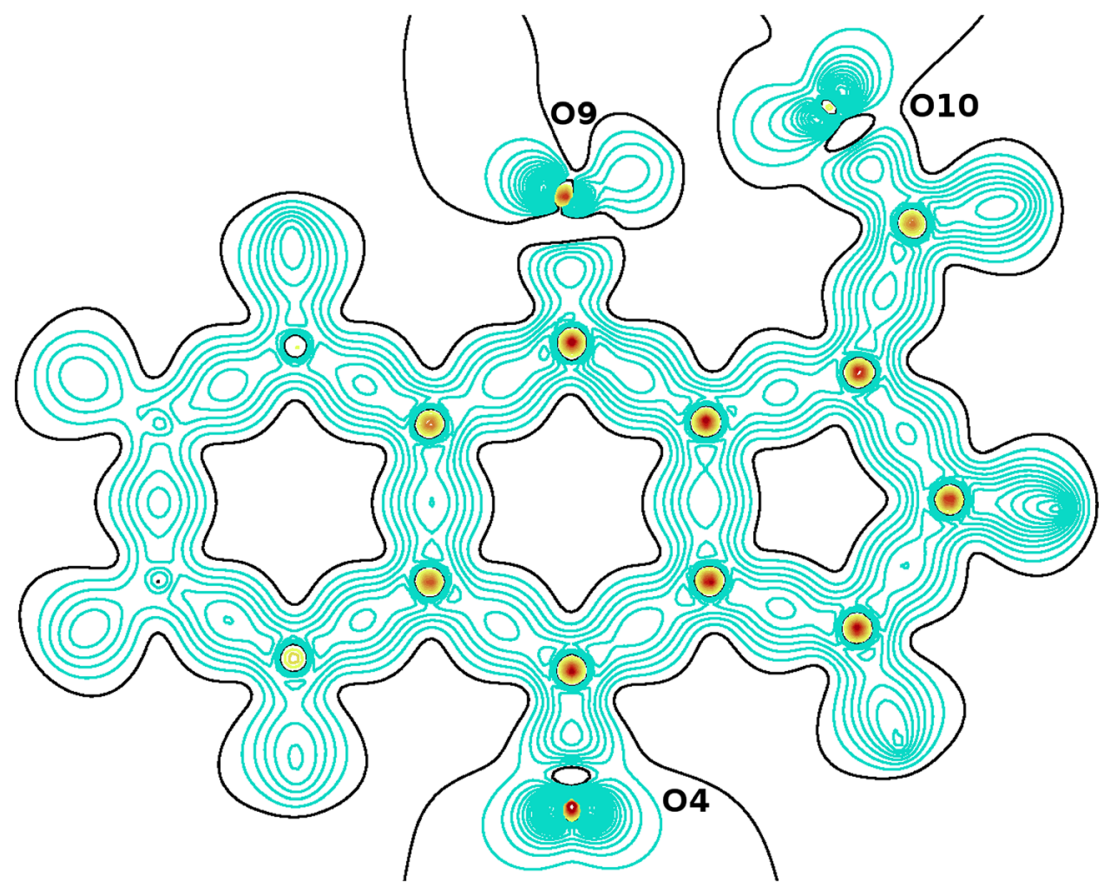

existence of $\mathbf{3 A}$ in the crystal structure cannot only be explained by the electronic differences in the resonance systems between $\mathbf{3 A}$ and 3B. Here, the intermolecular interactions energetically lower type $\mathbf{3 A}$ even more, whereas for structures such as ASELEP in Part I, the intermolecular interactions destabilized the electronically more stable isolated type $\mathbf{B}$ and realized type $\mathbf{A}$ in the crystal structures.

The Hirshfeld surface [62, 63] (Fig. 4a) shows a clear asymmetry in the intermolecular interaction network in terms of an intense red marker at $\mathrm{O} 10$, but none at $\mathrm{O} 9$. Oxygen atom $\mathrm{O} 10$ is acceptor of a $\mathrm{C}-\mathrm{H}$... O hydrogen bond (C3-H3 ...O10) that is significantly closer than the $\mathrm{C} 8-\mathrm{H} 8 \ldots$... 9 hydrogen

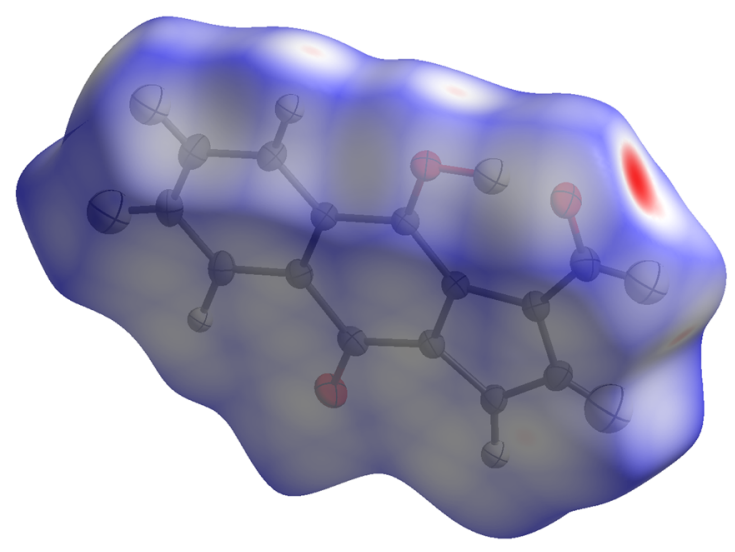

(a) bond that $\mathrm{O} 9$ is involved in as an acceptor, see also Table S8. It has been found before [33] that the hydrogen atom in the intramolecular hydrogen bond is always located closer to the oxygen atom that is less strongly involved in intermolecular interactions. This intermolecular packing effect is more important than the intramolecular electronic effect. Here, we find that the hydrogen is located closer to $\mathrm{O} 9$ than $\mathrm{O} 10$ as expected from reference [33] favouring tautomer $\mathbf{3 A}$, and it is also closer to the midpoint compared to an isolatedmolecule calculation. If a first molecule of the coordination sphere of 3, namely the one that forms the C3-H3...O10 hydrogen bond, is included in the theoretical calculation in the

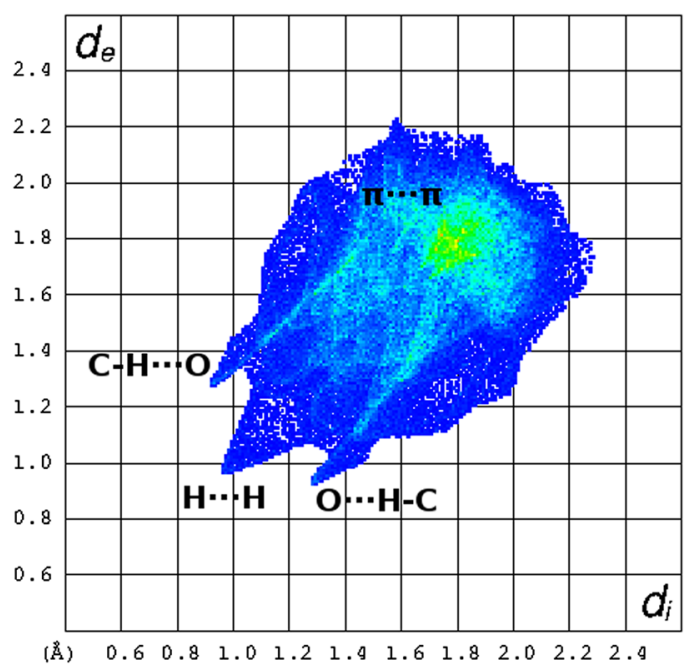

(b)

Fig. 4 a Hirshfeld surface with $d_{\text {norm }}$ [64] mapped onto it, colour scale: -0.308 (red) to 1.007 (blue), based on model HAR iso. b Fingerprint plot of the same Hirshfeld surface 


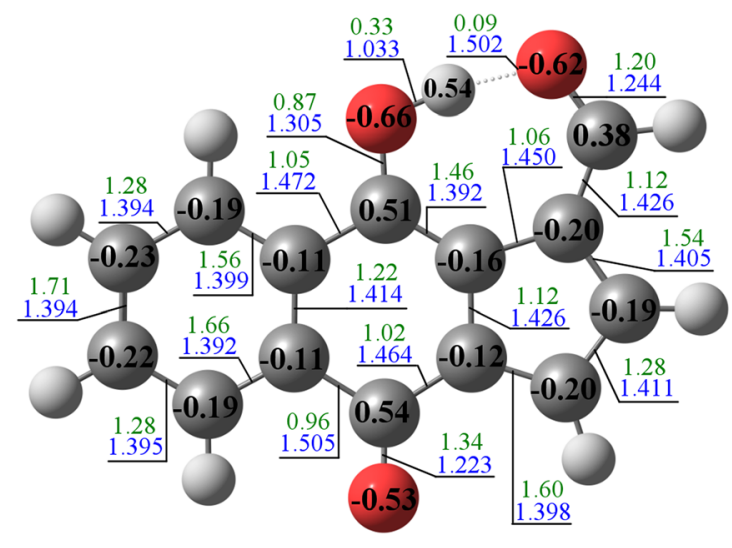

(a) $3 \mathrm{~A}$

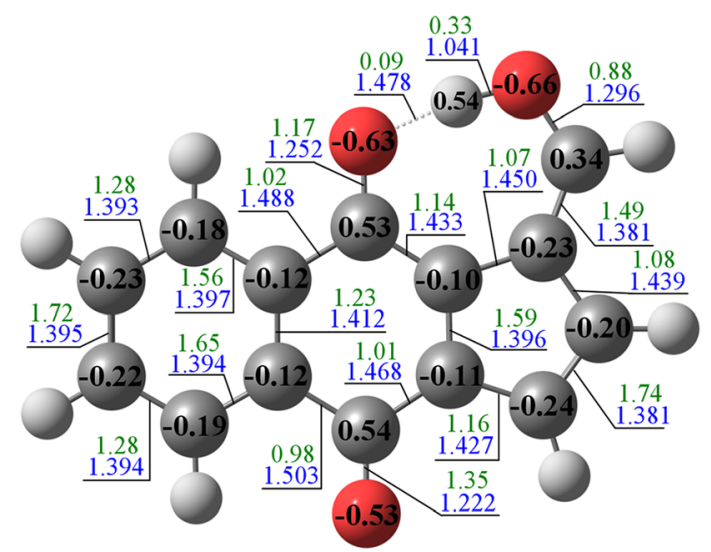

(b) $3 \mathbf{B}$

Fig. 5 Tautomers 3A and 3B with the optimized bond distance (in $\AA$, blue), the NLMO bond order (green) and the NPA charge (in e, black). Level of theory: B3LYP/6-31 + G(2df,p)

form of a dimer geometry optimization, it can be confirmed that the $\mathrm{O} 9-\mathrm{H}$ distance is slightly elongated and the $\mathrm{O} \ldots \mathrm{O}$ distance is slightly shortened in accord with the experimental finding (Table 4).

The $\mathrm{C}-\mathrm{H} . . . \mathrm{O}$ hydrogen bonds are represented as spikes in the fingerprint plot [65] (Fig. 4b) confirming the significance of these interactions in the crystal packing of $\mathbf{3 A}$ in the absence of hydrogen bond donors for classical intermolecular hydrogen bonds. Further intermolecular interactions (close $\mathrm{H}$...H and $\pi$-stacking) are also of high significance for the crystal lattice, and can be identified from the fingerprint plot. H...H contacts are as close as $1.93 \AA$ (Tables S9 and S10) and are responsible for $39.6 \%$ of all the interactions mediated through the Hirshfeld surface (Table S11) [66].

Despite the fact that we established that the intermolecular hydrogen bonding pattern is decisive for the positioning of the hydrogen atom in the intramolecular hydrogen bond, we strive for an understanding of the different electronic resonance systems in the types $\mathbf{3 A}$ and $\mathbf{3 B}$. To which extent does the position of the hydrogen atom influence the resonance system? Figure 5 summarizes the results from a natural bond orbital (NBO) analysis, [67] namely the natural population analysis (NPA) charges (black) and the natural localized molecular orbital (NLMO) bond orders (green) relative to the bond distance from the optimized isolated-state optimizations (blue). The bonding pattern sketched in Scheme 2 for $\mathbf{3 A}$ and $\mathbf{3 B}$ is indeed reflected in the bond orders. Whereas the charges and bond orders from atom $\mathrm{C} 3 \mathrm{~A}$ through to atom $\mathrm{C} 9$ including atom $\mathrm{O} 4$ are unchanged between $\mathbf{3 A}$ and $\mathbf{3 B}$, all atomic charges and bond orders belonging to the five-membered and the sevenmembered rings (the latter being formed by the RAHB) are altered significantly in line with the Lewis structures in Scheme 2, e.g., C10-O10, C1-C2, C3-C3A, C9-C9A have partial double-bond character in $\mathbf{3 A}$ (Fig. 5a), whereas in 3B the bonds between atoms $\mathrm{C} 1-\mathrm{C} 10, \mathrm{C} 2-\mathrm{C} 3, \mathrm{C} 3 \mathrm{~A}-\mathrm{C} 9 \mathrm{~A}$ and $\mathrm{C} 9-$ O9 have partial double-bond character (Fig. 5b).
In contrast to the simple Lewis structure representations in Scheme 2 that do not show resonance within each tautomer, the NBO analyses highlight that there is a significant degree of resonance in each tautomer system, i.e. those $\mathrm{C}-\mathrm{C}$ bonds with double-bond character have bond orders around 1.5 to 1.7 , and those $\mathrm{C}-\mathrm{C}$ bonds with single-bond character have bond orders around 1.1 to 1.2 . In the more polar $\mathrm{C}-\mathrm{O}$ and $\mathrm{O}-\mathrm{H}$ bonds, the bond order is decreased because ionic resonance forms are important, but are not included in the NLMO scheme. The charge of oxygen atom $\mathrm{O} 4$ is constant at $-0.53 \mathrm{e}$, whereas the charge on $\mathrm{O} 9$ and $\mathrm{O} 10$ varies by $0.04 \mathrm{e}$ depending on which oxygen atom carries the hydrogen atom. All carbon atoms in the rings are slightly negatively charged, but the carbonyl carbon atoms are significantly positively charged.

\section{Conclusion}

In Part I of this study, we have shown the importance of locating hydrogen atoms in X-ray crystallographic structures accurately using tautomerism in the compound class of acylpyrazolones as an example. Conventional ways of hydrogen atom treatment in X-ray data (independent atom model, geometric placement) fail, and the relevant tautomeric types $\mathbf{A}$ and $\mathbf{B}$ (enol) versus $\mathbf{C}$ and $\mathbf{D}$ (keto) can only be differentiated from each other on the basis of the non-hydrogen geometries that exhibit different resonance schemes in each tautomer type. Theoretical isolated-molecule calculations identify two energetically very similar minima in the potential energy for the enol types $\mathbf{A}$ and $\mathbf{B}$, that are significantly more stable than the keto form $\mathbf{D}$, a third minimum on the potential energy surface. However, all three forms A, B and $\mathbf{D}$ exist in crystal structures, which means that the cohesive energies are obviously larger than the intramolecular electronic stabilization energies through resonance. In summary, both conventional $\mathrm{X}$-ray diffraction and routine theoretical strategies fail for the 
prediction and analysis of tautomeric forms in crystal structures.

According to Massa, quantum crystallography is the combination of diffraction and theory into a single tool that leads to enhanced information contents of the wavefunction used, or to enhanced crystallographic information. The latter is fulfilled in Hirshfeld atom refinement, so that accurate hydrogen atom positions can be obtained from the diffraction data. This was shown in Part II of this study using compound $\mathbf{3}$, a novel photolysis product that possesses a resonance assisted hydrogen bond similar to the acyl-pyrazolones. Enolic form A could easily be discerned from form $\mathbf{B}$ based on the hydrogen atom position alone. HAR refinement on compound $\mathbf{3}$ is the first example of HAR using low-order data for a weakly scattering organic molecule. Free refinement of hydrogen anisotropic displacement parameters led to overall physically unreasonable results, despite the A-H distances being identical to the isotropic model. In a forthcoming study, we will investigate in more detail how the accuracy of the position in resonance assisted hydrogen bonds is influenced by the way of estimating or refining the hydrogen displacement parameters.

The positioning of the hydrogen atom in the two enol forms $\mathbf{A}$ and $\mathbf{B}$ is governed by the intermolecular interaction pattern that the two oxygen atoms are involved in. The hydrogen atom is located closer to the oxygen atom that is less strongly polarized by the environment through close intermolecular contacts. Moreover, the strength of the hydrogen bond is increased and the O...O distance shortened by crystal packing forces in general, relative to the isolated molecule approximation. We will analyse in a future study how the electric field imposed by the crystalline environment affects the $\mathrm{O}$... O distance and hydrogen position.

Acknowledgements We gratefully acknowledge useful consultations with Prof. C. Pettinari of the University of Camerino in respect of accessing/acquiring data on relevant compounds. S. Grabowsky thanks the German Research Foundation (Deutsche Forschungsgemeinschaft DFG) for funding within the Emmy Noether scheme GR 4451/1-1.

\section{Compliance with ethical standards}

Conflict of interest The authors declare that they have no conflict of interest.

\section{References}

1. Antonov L (2013) Tautomerism: methods and theories. John Wiley \& Sons,

2. Ädelroth P (2006) Special issue on proton transfer in biological systems Biochimica et Biophysica Acta (BBA)-Bioenergetics 1757(8):867-870

3. Geraldes C, Barros M, Maycock C, Silva M (1990) The preferential direction of enolization of some asymmetric 1, 3-dicarbonyl compounds in solution: a study by multinuclear NMR spectroscopy $\mathrm{J}$ Mol Struct 238:335-346
4. Allen G, Dwek RA (1966) An nmr study of keto-enol tautomerism in $\beta$-diketones. Journal of the Chemical Society B, Physical Organic, pp. 161-163

5. Zheglova D, Denkov N, Kol'tsov A (1984) Influence of intramolecular hydrogen bonds on the tautomeric equilibrium of 1,3diketones J Mol Struct 115:371-374

6. Jones RD (1976) The crystal structure of the enol tautomer of 1,3diphenyl-1,3-propanedione (dibenzoylmethane) by neutron diffraction Acta Crystallographica Section B: Structural Crystallography and Crystal Chemistry 32(6):1807-1811

7. Gilli G, Gilli P (2000) Towards an unified hydrogen-bond theory J Mol Struct 552(1):1-15

8. Cleland W (2000) Low-barrier hydrogen bonds and enzymatic catalysis Arch Biochem Biophys 382(1):1-5

9. Cleland WW, Kreevoy MM (1994) Low-barrier hydrogen bonds and enzymic catalysis Science 264(5167):1887-1887

10. Schiøtt B, Iversen BB, Madsen GKH, Larsen FK, Bruice TC (1998) On the electronic nature of low-barrier hydrogen bonds in enzymatic reactions Proc Natl Acad Sci 95(22):12799-12802

11. CCDC (2014) ConQuest version 1.17- CSD version 5.36 (May 2015)

12. Akama Y, Shiro M, Ueda T, Kajitani M (1995) Keto and enol tautomers of 4-benzoyl-3-methyl-1-phenyl-5 (2H)-pyrazolone Acta Crystallogr Sect C: Cryst Struct Commun 51(7):1310-1314 (CCDC: YUYDOL (enol), DEBFAR02 (keto))

13. Gloe K, Uzoukwu BA, Rademacher O (2000) 4-acetyl-5-methyl-2phenyl-1, 2-dihydro-3H-pyrazol-3-one hydrate Acta Crystallogr Sect C: Cryst Struct Commun 56(12):e580-e581 (CCDC: XEGVEK)

14. Holzer W, Mereiter K, Plagens B (1999) 4-acyl-5-methyl-2phenylpyrazolones: NMR and X-ray structure investigations Heterocycles 2(50):799-818 (CCDC: CIQFEN (enol), CIQDUB (enol), CIQFAJ (keto))

15. Guard JA, Steel PJ (1994) Heterocyclic tautomerism. VII. X-ray structures of two crystalline tautomers of 4-cinnamoyl-1, 3dimethylpyrazol-5-one Aust J Chem 47(8):1453-1459 (CCDC: HESTUU (enol), HESTOO (keto))

16. Kataeva ON, Gubaidullin AT, Litvinov IA, Lodochnikova OA, Islamov LR, Movchan AI, Chmutova GA (2002) The structure of 1-phenyl-3-benzoylamino-4-benzoylpyrazol-2-in-5-one J Mol Struct 610(1):175-179 (CCDC: MUGQIO)

17. Cingolani A, Marchetti F, Pettinari C, Pettinari R, Skelton BW, White AH (2004) A 4-acyl-5-pyrazolone ligand (HQ) in Nunidentate coordination mode in a $\mathrm{Rh}(\mathrm{CO})_{2} \mathrm{Cl}(\mathrm{HQ})$-type complex Inorg Chem Commun 7(2):235-237 (CCDC: ASELEP)

18. Pettinari R, Pettinari C, Marchetti F, Skelton BW, White AH, Bonfili L, Cuccioloni M, Mozzicafreddo M, Cecarini V, Angeletti M (2014) Arene-ruthenium (II) acylpyrazolonato complexes: apoptosis-promoting effects on human cancer cells J Med Chem 57(11):4532-4542 (CCDC: ZOJZAB)

19. Pettinari C, Marchetti F, Pettinari R, Natanti P, Drozdov A, Semenov S, Troyanov SI, Zolin V (2006) Syntheses, spectroscopic characterization and X-ray structural studies of lanthanide complexes with adamantyl substituted 4-acylpyrazol-5-one Inorg Chim Acta 359(12):4063-4070 (CCDC: MELNEX)

20. Remya P, Suresh C, Reddy M (2007) Rapid reduction and complexation of vanadium by 1-phenyl-3-methyl-4-toluoyl-5pyrazolone: spectroscopic characterization and structure modelling Polyhedron 26(17):5016-5022 (CCDC: VIMPAJ)

21. Cingolani A, Effendy, Marchetti F, Pettinari C, Pettinari R, Skelton BW, White AH (2002) First structurally characterized silver (I) derivatives with nonfluorinated $\beta$-Diketones Inorg Chem 41(5): 1151-1161 (C2/c phase; CCDC: ADURIA)

22. Sheikh TU, Khan MA, Arshad MN, Khan IU, Stoeckli-Evans H (2009) 1-(5-Hydroxy-3-methyl-1-phenyl-1H-pyrazol-4-yl) ethanone: a new monoclinic polymorph Acta Crystallogr Sect E: 
Struct Rep Online 65(2):0330-o330 (P21/n phase; CCDC: ADURIA01)

23. Shi M, Li F, Yi T, Zhang D, Hu H, Huang C (2005) Tuning the triplet energy levels of pyrazolone ligands to match the 5D0 level of europium (III) Inorg Chem 44(24):8929-8936 (CCDC: RAXXUK)

24. Begantsova YE, Bochkarev LN, Malysheva IP, Stolyarova NE, Kurskii YA, Lopatin MA, Baranov EV, Ilichev VA, Abakumov GA, Bochkarev MN (2011) Synthesis, photo-and electroluminescent properties of norbornene based platinum-containing copolymers Synth Met 161(11):1043-1050 (CCDC: ASUPUA)

25. Uzoukwu AB, Al-Juaid SS, Hitchcock PB, Smith JD (1993) The synthesis and crystal structures of 1-phenyl-3-methyl-4butanolypyrazol-5-one and of two pyrazolonato complexes of iron Polyhedron 12(22):2719-2724 (CCDC: LELDIP)

26. O'Connell M, Ramsay C, Steel P (1985) Heterocyclic Tautomerism. II. 4-Acylpyrazolones. X-ray crystal structures of 4-benzoyl-5methyl-2-phenylpyrazol-3 (2H)-one and 4-Acetoacetyl-3-methyl1-phenylpyrazol-5-ol Aust J Chem 38(3):401-409 (CCDC: DEBFAR, DEBFEV)

27. Marchetti F, Marinelli A, Pettinari C, Skelton BW, White AH (2011) Binuclear diorganotin (IV) complexes with bis (O, O'-4acyl-5-pyrazolonato) bis (bidentate) ligands Inorg Chim Acta 366(1):388-393 (CCDC: ULUFOX)

28. Deng G-M, Zhang H-M, Ou-Yang L-Q, Tong Q-Z, Li S (2012) [1(4-Chlorophenyl)-5-hydroxy-3-phenyl-1H-pyrazol-4-yl](thiophen2-yl) methanone Acta Crystallogr Sect E: Struct Rep Online 68(6): o1639-o1639 (CCDC: PAXWUI)

29. Li J-Z, Zhang H-Q, Li H-X, Che P-Z, Wang T-C (2007) 1-(4Chlorophenyl)-4-(2-furoyl)-3-(2-furyl)-1H-pyrazol-5-ol Acta Crystallogr Sect E: Struct Rep Online 63(3):o1289-o1290 (CCDC: DEYSIK)

30. Elguero J (2011) Polymorphism and desmotropy in heterocyclic crystal structures Cryst Growth Des 11(11):4731-4738

31. Desiraju GR (2008) Polymorphism: the same and not quite the same Crystal Growth Des 8(1):3-5

32. Marchetti F, Pettinari C, Pettinari R (2005) Acylpyrazolone ligands: synthesis, structures, metal coordination chemistry and applications Coord Chem Rev 249(24):2909-2945

33. Malaspina LA, Edwards AJ, Woinska M, Jayatilaka D, Turner MJ, Price JR, Herbst-Irmer R, Sugimoto K, Nishibori E, Grabowsky S (2017) Predicting the position of the hydrogen atom in the short intramolecular hydrogen bond of the hydrogen maleate anion from geometric correlations Cryst Growth Des 17:3812-3825

34. Hoser AA, Dominiak PM, Woźniak K (2009) Towards the best model for $\mathrm{H}$ atoms in experimental charge-density refinement Acta Crystallogr A: Found Crystallogr 65(4):300-311

35. Allen FH, Bruno IJ (2010) Bond lengths in organic and metalorganic compounds revisited: $\mathrm{X}-\mathrm{H}$ bond lengths from neutron diffraction data Acta Crystallogr Sect B: Struct Sci 66(3):380-386

36. Lusi M, Barbour LJ (2011) Determining hydrogen atom positions for hydrogen bonded interactions: a distance-dependent neutronnormalized method Crystal Growth Des 11(12):5515-5521

37. Deringer VL, Hoepfner V, Dronskowski R (2012) Accurate hydrogen positions in organic crystals: assessing a quantum-chemical aide Cryst Growth Des 12(2):1014-1021

38. Dittrich B, Lübben J, Mebs S, Wagner A, Luger P, Flaig R (2017) Accurate bond lengths to hydrogen atoms from single-crystal X-ray diffraction by including estimated hydrogen ADPs and comparison to neutron and QM/MM benchmarks Chem Eur J 23:4605-4614

39. Dittrich B, Hübschle C, Pröpper K, Dietrich F, Stolper T, Holstein J (2013) The generalized invariom database (GID) Acta Crystallogr Sect B: Struct Sci Cryst Eng Mater 69(2):91-104

40. Jarzembska KN, Dominiak PM (2012) New version of the theoretical databank of transferable aspherical pseudoatoms, UBDB2011- towards nucleic acid modelling Acta Crystallogr A: Found Crystallogr 68(1):139-147

41. Domagała S, Fournier B, Liebschner D, Guillot B, Jelsch C (2012) An improved experimental databank of transferable multipolar atom models-ELMAM2. Construction details and applications Acta Crystallogr A: Found Crystallogr 68(3):337-351

42. Jayatilaka D, Dittrich B (2008) X-ray structure refinement using aspherical atomic density functions obtained from quantummechanical calculations Acta Crystallogr A: Found Crystallogr 64(3):383-393

43. Capelli SC, Bürgi HB, Dittrich B, Grabowsky S, Jayatilaka D (2014) Hirshfeld atom refinement IUCrJ 1(5):361-379

44. Woińska M, Grabowsky S, Dominiak PM, Woźniak K, Jayatilaka D (2016) Hydrogen atoms can be located accurately and precisely by x-ray crystallography Sci Adv 2(5):e1600192

45. Woińska M, Jayatilaka D, Spackman MA, Edwards AJ, Dominiak PM, Wozniak K, Nishibori E, Sugimoto K, Grabowsky S (2014) Hirshfeld atom refinement for modelling strong hydrogen bonds Acta Crystallogr Section A: Found Adv 70(5):483-498

46. Grabowsky S, Genoni A, Bürgi HB (2017) Quantum crystallography Chem Sci 8:4159-4176

47. Massa L, Huang L, Karle J (1995) Quantum crystallography and the use of kernel projector matrices Int J Quantum Chem 56(S29): 371-384

48. Huang L, Massa L, Karle J (1999) Quantum crystallography applied to crystalline maleic anhydride Int J Quantum Chem 73(5): $439-450$

49. Sheldrick GM (2008) A short history of SHELX Acta Crystallogr Section A 64(1):112-122

50. Wege D (1998) In: Thummel RP (ed) Advances in theoretically interesting molecules, vol 4. JAI Press Inc., Stamford, Connecticut, and London, U.K.

51. Hixson SS, Mariano PS, Zimmerman HE (1973) Di-. pi.-methane and oxa-di-. pi.-methane rearrangements Chem Rev 73(5):531-551

52. Karichiappan K, Wege D (2000) Naphtho[2,3-c]furan-4,9-dione and a further exploratory approach to the ring system of Ventilone A Aust J Chem 53(9):743-747

53. Hirshfeld FL (1977) Bonded-atom fragments for describing molecular charge densities Theor Chim Acta 44(2):129-138

54. Hirshfeld FL (1977) XVII. Spatial partitioning of charge density Israel J Chem 16(2-3):198-201

55. Frisch M, Trucks G, Schlegel H, Scuseria G, Robb M, Cheeseman J, Scalmani G, Barone V, Mennucci B, Petersson G, Nakatsuji H, Caricato M, Li X, Hratchian HP, Izmaylov AF, Bloino J, Zheng G, Sonnenberg JL, Hada M, Ehara M, Toyota K, Fukuda R, Hasegawa J, Ishida M, Nakajima T, Honda Y, Kitao O, Nakai H, Vreven T, Montgomery Jr JA, Peralta JE, Ogliaro F, Bearpark M, Heyd JJ, Brothers E, Kudin KN, Staroverov VN, Keith T, Kobayashi R, Normand J, Raghavachari K, Rendell A, Burant JC, Iyengar SS, Tomasi J, Cossi M, Rega N, Millam JM, Klene M, Knox JE, Cross JB, Bakken V, Adamo C, Jaramillo J, Gomperts R, Stratmann RE, Yazyev O, Austin AJ, Cammi R, Pomelli C, Ochterski JW, Martin RL, Morokuma K, Zakrzewski VG, Voth GA, Salvador P, Dannenberg JJ, Dapprich S, Daniels AD, Farkas O, Foresman JB, Ortiz JV, Cioslowski J, Fox DJ (2009) Gaussian 09, revision D. 01. Gaussian, Inc., Wallingford CT,

56. Glendening ED, Landis CR, Weinhold F (2013) NBO 6.0: natural bond orbital analysis program J Comput Chem 34(16):1429-1437

57. Koritsanszky T, Howard S, Macchi P, Gatti C, Farrugia L, Mallinson P, Volkov A, Su Z, Richter T, Hansen N (2003) XD (version 4.10, July), a computer program package for multipole refinement and analysis of electron densities from diffraction data. Free University of Berlin, Germany,

58. Wolff SK, Grimwood DJ, McKinnon JJ, Turner MJ, Jayatilaka D, Spackman MA (2012) CrystalExplorer (Version 3.1) 
59. Miao Fangming LX, Yongqiang L (1991) Wuji Huaxue Xuebao Chinese J Inorg Chem 7(6):129-132 (CCDC: DEBFAR01)

60. Steiner T (2002) The hydrogen bond in the solid state Angew Chem Int Ed 41(1):48-76

61. Goerigk L, Grimme S (2011) A thorough benchmark of density functional methods for general main group thermochemistry, kinetics, and noncovalent interactions Phys Chem Chem Phys 13(14): 6670-6688

62. Spackman MA, Byrom PG (1997) A novel definition of a molecule in a crystal Chem Phys Lett 267(3-4):215-220

63. Spackman MA, Jayatilaka D (2009) Hirshfeld surface analysis Cryst Eng Comm 11(1):19-32
64. McKinnon JJ, Jayatilaka D, Spackman MA (2007) Towards quantitative analysis of intermolecular interactions with Hirshfeld surfaces Chem Commun 37:3814-3816

65. Spackman MA, McKinnon JJ (2002) Fingerprinting intermolecular interactions in molecular crystals Cryst Eng Comm 4(66):378-392

66. Matta CF, Hernández-Trujillo J, Tang TH, Bader RFW (2003) Hydrogen-hydrogen bonding: a stabilizing interaction in molecules and crystals Chem Eur J 9:1940-1951

67. Weinhold F, Landis CR (2001) Natural bond orbitals and extensions of localized bonding concepts Chem Educ Res Pract 2(2):91-104 